\title{
Considering hazard estimation uncertain in urban resilience strategies
}

\author{
B. Barroca ${ }^{1}$, P. Bernardara ${ }^{2}$, S. Girard ${ }^{3}$, and G. Mazo $^{3}$ \\ ${ }^{1}$ Lab’Urba, Paris-Est university, 5 Bd Descartes, 77454 Marne-La-Vallée, France \\ ${ }^{2}$ EDF Energy R\&D UK Centre, London, UK \\ ${ }^{3}$ Team Mistis, Inria Grenoble Rhône-Alpes \& LJK, Inovallée, 655, av. de l'Europe, Montbonnot, \\ 38334 Saint-Ismier CEDEX, France
}

Correspondence to: B. Barroca (bruno.barroca@u-pem.fr), S. Girard (stephane.girard@inria.fr)

Received: 16 January 2014 - Published in Nat. Hazards Earth Syst. Sci. Discuss.: 11 June 2014

Revised: - - Accepted: 13 October 2014 - Published: 6 January 2015

\begin{abstract}
Urbanization has led to a higher concentration of both persons and property, which increases the potential degree of damage liable to occur in crisis situations. Urban areas have become increasingly complex socio-technical systems where the inextricable tangle of activities, networks and regions means disruptions propagate rather than disseminate.

In risk anticipation, measures of prevention and anticipation are generally defined by using hazard modelling. The relevance of this approach may be subject to discussion (Zevenbergen et al., 2011) particularly in view of the large number of uncertainties that make hazard evaluation so difficult. For this reason, uncertainty analysis is initially called upon in a theoretical approach before any applied approach. Generally, the uncertainty under study is not assessed in hydrological studies. This uncertainty is related to the choice of evaluation model used for extreme values. This application has been used on the territory of the town of Besançon in eastern France. Strategic orientations for regional resilience are presented taking into account the high levels of uncertainty concerning estimates for possible flow rates.
\end{abstract}

\section{Introduction}

Climate change, combined with a higher concentration of property and persons in urban areas and the increasing sensitiveness of our urban systems, foretell devastating events for the years to come. By the end of the century, the economic cost of flood risks throughout the world is liable to attain a value of EUR 100 billion per year (EEA, 2011).
Aside from exceptional cases, de-urbanizing flood areas is out of the question due to economic development (Klein et al., 2004), social acceptance (Adger et al., 2008) and the environmental challenges raised by sustainable development, which include limiting urban sprawl by increasing city density and compactness. Therefore, the fight against damage caused by flooding, as well as the sustainable development objectives that apply to urban technical systems, mean that resilience actions must be implemented (Milman and Short, 2008). If hazards prove to be interesting factors of innovation for cities and buildings (Romero-Lankao and Dodman, 2011), risk management measures must be taken in an appropriate context of governance and with adequate knowledge of any changes in socio-economic contexts and uncertainties (Adger et al., 2008). Research on vulnerability has increased over the last few years (Serre and Barroca, 2013; Birkmann et al., 2013). This type of research normally assesses a city's vulnerability to a hazard and sometimes introduce resilience indicators, strategies or adaptation scenarios (Barroca et al., 2006; Romero-Lankao and Qin, 2011). If various authors agree to admit that, for anticipating flooding efficiently, implementation of resilient strategies must anticipate flooding scenarios, which today's probabilistic models deem to be extreme or rare (Zevenbergen et al., 2011), it would appear necessary to put the reliability of these results into question.

For modelling hazards, especially hydrological hazards, we cannot exclude important uncertainties, especially when modelling rare events (Barroca, 2006). Improving risk management for events that possess considerable evaluation 
uncertainty must integrate this uncertainty into strategic orientations. In this article, strategic analysis is developed by characterizing regions for implementing resilience by incorporating uncertainty in hazard evaluations. This article does not deal with the holistic problem of resilience, which involves cultural, social, environmental, economic and institutional resilience and the link between the various facets. To implement a local strategy, the central aim of this article is to develop an approach for understanding the importance of urban components and critical infrastructures.

A method for evaluating the uncertainty due to extreme events is presented in Sect. 2 and is illustrated in Sect. 3 on the Besançon data set. A guiding action for regional resilience is proposed in Sect. 4 and concluding remarks are provided in Sect. 5.

\section{Statistical evaluation of uncertainty}

On several rivers, the high discharges observed over recent years exceed the prediction of very rare quantile carried out in the past by hydrologists. Two main explanations exist:

- These floods are very extreme and their probability of occurrence is very small.

- These floods are important, but their "beyond the norm" nature is merely wishful thinking. This illusion is perpetuated by errors inherent to estimates of their return period which, on the face of it, are too great.

To identify a flood-prone area in the event of a rise in water levels - 100-year flooding for example - we need to make a series of analyses and choices. Uncertainties exist at every stage, which makes estimating global uncertainty an extremely complex task.

This section presents the characterization of uncertainties, especially the uncertainty as to the choice of mathematical model to be used for estimating the hazard.

We will not go into measurement uncertainty (Lang et al., 2006; Gaume et al., 2004) nor the validity of sometimes obsolete measurements in a context of climate change. Uncertainties on the physical model are generally circumscribed, but uncertainties related to the choice of mathematical model used for estimating extreme flow rates are not presented in risk analyses. Hydrologists' culture (in the sense of their usual habits) leads them to systematically use the so-called Gumbel model without assessing its relevance in the face of data distribution (Payrastre et al., 2005; Payrastre, 2005; Bernardara et al., 2008).

\subsection{Extreme-value theory}

Extreme-value theory is a relevant tool for estimating $N$-year return level (denoted by $T_{N}$ ) of floods or rainfalls when $N$ is larger than the number of years of observations. In such a case, $T_{N}$ is beyond the observation range and extrapolation is thus needed. Extreme-value theory provides several estimators as well as evaluations of their associated uncertainty through the construction of confidence intervals. Two types of methods are available; see Coles (2001) for further details.

\subsubsection{Block maxima approach}

Let $X_{1}, X_{2}, \ldots$ be a sequence of independent random variables with a common distribution function $F$. Denoted by $M_{n}=\max \left(X_{1}, \ldots, X_{n}\right)$ their maxima with distribution function $F^{n}$. The extreme-value theory states that the distribution function of their maxima can be approximated by the generalized extreme value (GEV) distribution function defined as

$$
G_{\xi}(x)=\exp \left[-\left(1+\xi\left(\frac{x-\mu}{\sigma}\right)\right)^{-1 / \xi}\right]
$$

for all $x$ such that $1+\xi(x-\mu) / \sigma>0$. Here, $\mu$ is the location parameter, $\sigma>0$ is the scale parameter and $\xi$ is the shape parameter referred to as the extreme-value index. In the particular case where $\xi=0$, the GEV reduces to a Gumbel distribution:

$G_{0}(x)=\exp \left[-\exp \left(-\left(\frac{x-\mu}{\sigma}\right)\right)\right]$.

Otherwise, the GEV distribution is called a Fréchet distribution $(\xi>0)$ or a Weibull distribution $(\xi<0)$. In practice, the original data $X_{1}, X_{2}, \ldots$ are split into $m$ blocks of size $n$. For instance, a block may correspond to a time period of length one year. In such a case, $n$ is the number of observations per year and thus the block maxima are annual maxima.

The $N$-year return period is then obtained by inverting $G_{\xi}$ at point $1 / N$ :

$$
T_{N}=\mu-\frac{\sigma}{\xi}\left[1-(-\log (1-1 / N))^{-\xi}\right] \simeq \mu-\frac{\sigma}{\xi}\left[1-N^{\xi}\right] \quad \text { if } \xi \neq 0
$$

or

$T_{N}=\mu-\sigma \log (-\log (1-1 / N)) \simeq \mu+\sigma \log N \quad$ if $\xi=0$,

the previous approximations being reliable if $N$ is large.

In practice, the parameters $(\mu, \sigma, \xi)$ have to be estimated. Several techniques exist, the two most popular being maximum likelihood and probability weighted moments. Both of them require an interactive procedure to compute the estimators. In each case, confidence intervals on return period to assess the statistical uncertainty of the estimation. However, in the block maxima approach, the estimation depends on the choices made by the user: the size of the blocks, the assumption made on the extreme-value index $(\xi \neq 0$ or $\xi=0)$ and the estimator used (maximum likelihood or probability weighted moments). Unfortunately, there is no mathematical tool to assess the uncertainty related to these choices. 


\subsubsection{Peaks over threshold (POT) approach}

The previous block maxima approach relies on the modelling of one single observation in each block: the maxima. There might be a loss of information if more than one observation is extreme in a block. To overcome this limitation, the POT approach relies on the modelling of the excesses over a threshold $u$. More specifically, the distribution of the $Y_{i}=X_{i}-u$ given $X_{i}>0$ can be approximated by a generalized Pareto distribution (GPD) with distribution function given by

$H_{\xi}(x)=1-\left(1+\xi \frac{x}{\lambda}\right)^{-1 / \xi}$

for all $x>0$, such that $1+\xi x / \lambda>0$. Here $\lambda>0$ is a scale parameter which can be expressed as a function of the GEV parameters as $\lambda=\sigma+\xi(u-\mu)$. The shape parameters coincides with the one of the GEV distribution. In the particular case where $\xi=0$, the GPD reduces to an exponential distribution:

$H_{0}(x)=1-\exp (-x / \lambda)$

Letting $p=P(X>u)$ and recalling that, for $x>u$,

$H_{\xi}(x-u) \simeq P\left(X_{i}>x \mid X_{i}>u\right)=P\left(X_{i}>x\right) / P\left(X_{i}>u\right)$,

one gets the approximation $P\left(X_{i}>x\right) \simeq p H_{\xi}(x-u)$. The $N$-year return period can then be obtained by inverting this formula at point $1 / N$ :

$T_{N}=u-\frac{\lambda}{\xi}\left[1-(N p)^{\xi}\right] \quad$ if $\xi \neq 0$

or

$T_{N}=u+\lambda \log (N p) \quad$ if $\xi=0$.

In practice, the proportion $p$ of observations exceeding the threshold $u$ is fixed by the user. Then, the threshold is estimated by the corresponding empirical quantile. The two remaining parameters $(\lambda, \xi)$ are estimated as previously via maximum likelihood or probability weighted moments. Here, the estimators are closed form, their computation is straightforward. Similarly to the block maxima approach, it is possible to compute confidence intervals on return period to assess the statistical uncertainty of the estimation. Again, the estimation depends on the choices made by the user: the proportion $p$ of excesses, the assumption made on the extreme-value index $(\xi \neq 0$ or $\xi=0)$ and the estimator used (maximum likelihood or probability weighted moments).

\section{Discussion}

As a conclusion, extreme-value theory offers a nice framework for the estimation of return levels $T_{N}$ via block maxima or excesses modelling. The expressions of $T_{N}$ are similar for the two approaches: $u$ corresponds to $\mu$ while $\lambda$ corresponds to $\sigma$ in the block maxima technique. It appears that the only difference between both methods relies on the estimation of the parameters. The POT approach benefits from easy implementation due to the existence of closed-form estimators. Extreme-value theory also permits a partial evaluation of the statistical uncertainty. However, the uncertainty may be under-estimated since the variability induced by the many choices left to the user is not taken into account. The variability can also be reduced by taking into account some covariate information such as geographical location (see Ceresetti et al., 2012; Gardes and Girard, 2010).

\section{Application to the Besançon analysis}

Besançon is a very important town, established during the Gallo-Roman period (with the name of Vesontio) and located in eastern France in a unique geographical location. In the centre is a meander of the Doubs River, which is almost a kilometre in diameter in the shape of an almost perfect closed loop virtually forming a peninsular and dominated by Mount Saint-Étienne, a high plateau facing the Jura mountains. At present, Besançon is the 30th largest city of France with 117392 inhabitants. It is considerably prone to flooding. The Doubs River 1910 flood, which occurred on 20 and 21 January of that year in the heart of the Franche-Comté region, is the reference used today. The 1910 water levels flooded half the city to levels of up to $1.5 \mathrm{~m}$ deep, or $72 \mathrm{~cm}$ higher than the previous 1882 floods. Historical research reveals that important floods also occurred in 1364, 1456, 1570, 1776, 1789 and 1802.

Besançon possesses a flood risk prevention plan for adapting its risk management policy.

\section{Data description}

Over 75 years of data on flow rates have been used for developing the flood risk prevention plan in Besançon. The Doubs River 100-year flood at Besançon is estimated as having a flow rate of $1750 \mathrm{~m}^{3}$ per second, whereas the flow rate for the 1910 flood, the most serious flood known, was estimated at $1610 \mathrm{~m}^{3}$ per second. Soil sealing as a result of urbanization increases run-off and restricts infiltration. Heavy rainfall results in so-called storm water flooding locally and generally an increase in downstream water flow that can induce so-called river floods caused by overflowing.

The data used for estimating extreme flow rates using the method presented above come from the hydrological data bank which is the reference flow-rate database in France.

\subsection{Numerical illustration - results}

In our block maxima implementation, each block corresponds to one year. We thus have 59 maxima to fit the GEV 
Table 1. Estimated 100-year return levels.

\begin{tabular}{lrr}
\hline & $\begin{array}{r}\text { Block } \\
\text { maxima }\end{array}$ & $\begin{array}{r}\text { Peaks other } \\
\text { threshold }\end{array}$ \\
\hline $\begin{array}{lrr}\text { Maximum likelihood } \\
\xi \neq 0\end{array}$ & 1331 & 1341 \\
$\xi=0$ & 1209 & 1525 \\
Probability weighted & 1235 & 1328 \\
moments & & \\
\hline
\end{tabular}

distribution. The estimation of the return levels is displayed in Fig. 1. On the top panel, the sample estimations (crosses) are compared to the estimation with the $G_{\xi}$ GEV model (continuous line). On the bottom panel, they are compared to the $G_{0}$ Gumbel model. It appears that, in both cases, sample estimates and model estimates are very close. Moreover, the sample estimates are always included in the corresponding $95 \%$ confidence intervals. These results indicate a very good fit of the GEV model for $\xi \neq 0$ or $\xi=0$. The estimated 100year return levels are reported in Table 1 . They are compared to these obtained with the probability weighted moments estimation of the GEV parameters.

Turning to the POT approach, the first step is the selection of an appropriate threshold $u$. The selection is achieved using the mean excess function defined as $m(t)=E(X-t \mid X>t)$. It is known that this function should be linear for all $t>u$. The method consists in plotting an estimation of $m(t)$ and choosing $u$ as the smallest value for which $m(t)$ is linear for all $t>u$. The graph of the so-called mean residual life plot is depicted in Fig. 3. Taking the confidence intervals into account, it appears the graph curves between $t=0$ and $t=350$. Beyond this interval, the graph is approximately linear until $t=900$. However, the estimation is very unstable for $t>900$, since it is based on very few points. This well-known phenomena is confirmed by the wide confidence intervals. We thus choose to work with a threshold fixed at $u=350$ leading to 867 excesses. We refer to Neves and Fraga Alves (2004) for a discussion on automatic methods for selecting the threshold. The estimation of the return levels with the corresponding GPD approach is displayed in Fig. 2. On the top panel, the sample estimations (crosses) are compared to the estimation with the $H_{\xi}$ GPD model (continuous line). On the bottom panel, they are compared to the $H_{0}$ exponential model. It appears that, in the first case $(\xi \neq 0)$, sample estimates and model estimates are very close. Moreover, the sample estimates are always included in the corresponding $95 \%$ confidence intervals. Let us also highlight that the confidence intervals obtained with the GPD approach are smaller than those obtained with the GEV approach since the GPD estimates are based on more points. The fit of the exponential distribution $(\xi=0)$ seems to be slightly worse for large return periods. The estimated 100-year return levels are reported in Table 1. They are compared to these ob-
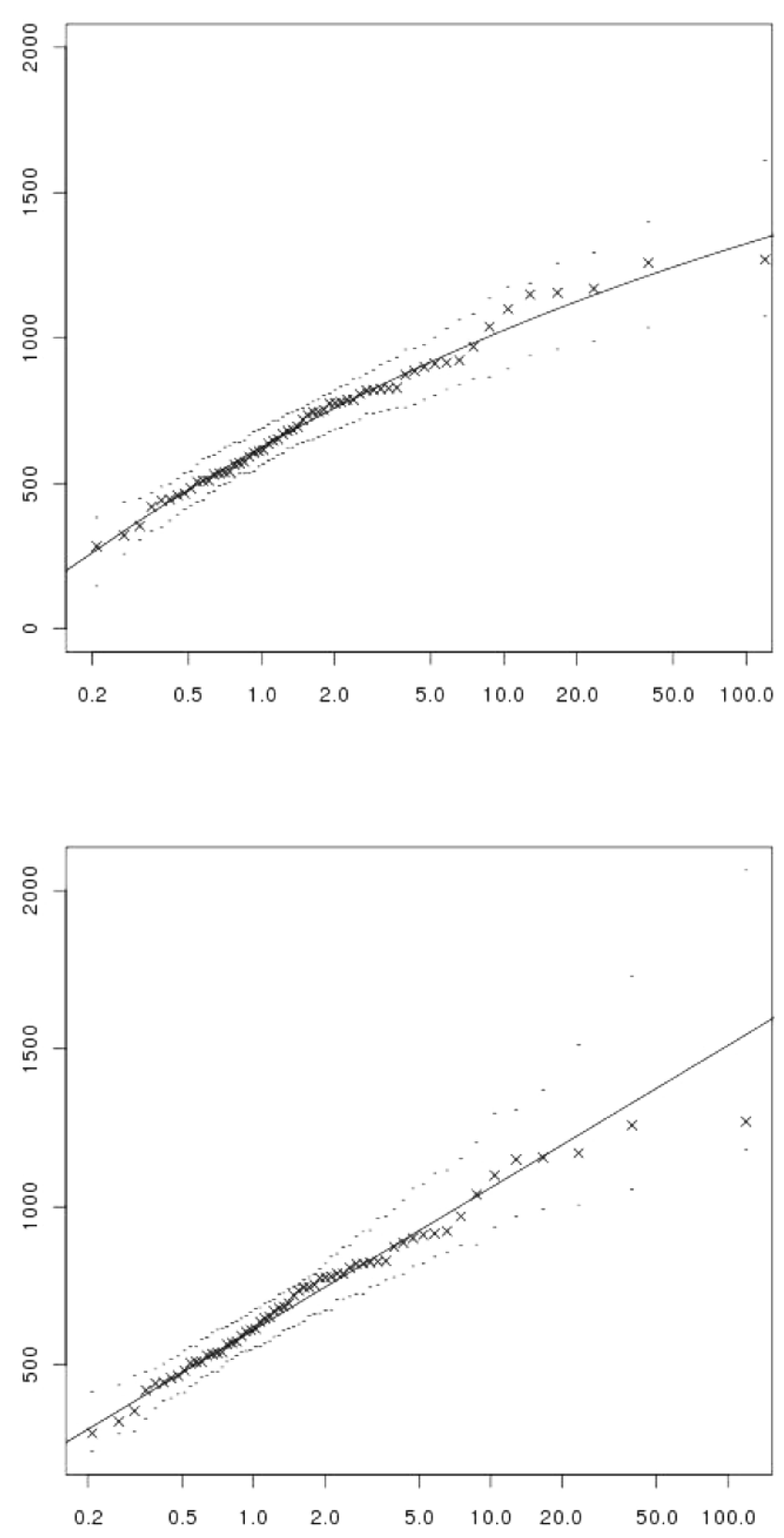

Figure 1. Return level plot (block maxima approach, maximum likelihood estimators). Top: assumption $\xi \neq 0$, bottom: assumption $\xi=0$. Horizontally: $-1 / \log (1-1 / N)$, logarithmic scale, vertically: estimated $N$-year return level. Continuous line: estimation using the GEV, crosses: sample points, dots: $95 \%$ confidence interval.

tained with the probability weighted moments estimation of the GPD parameters.

To summarize, excluding the results obtained with the exponential distribution (POT approach, $\xi=0$ ), we end up with five estimations of the 100-year return level ranging from 1209 (block maxima, $\xi=0$ ) to 1341 (POT, $\xi \neq 0$ ). Besides, the confidence intervals displayed on Figs. 1 and 2 provide an assessment of the uncertainty of each individual 

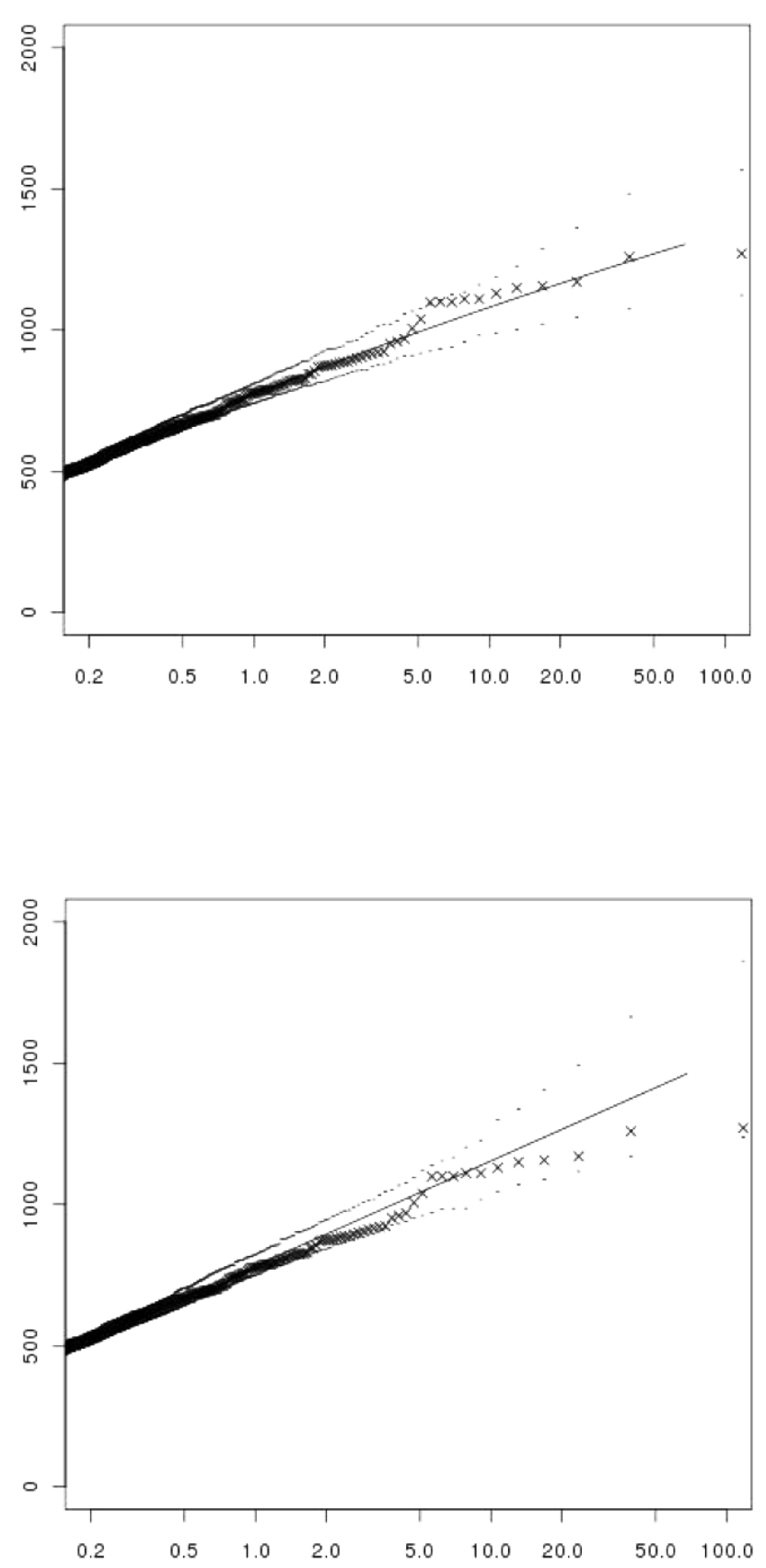

Figure 2. Return level plot (POT approach, maximum likelihood estimators). Top: assumption $\xi \neq 0$, bottom: assumption $\xi=0$. Horizontally: $-1 / \log (1-1 / N)$, logarithmic scale, vertically: estimated $N$-year return level. Continuous line: estimation using the GPD, crosses: sample points, dots: $95 \%$ confidence interval.

estimation. It appears that each of these five estimations belongs to the four $95 \%$ confidence intervals computed with the other methods. This highlights the consistency between the estimations. However, we do not have any assessment of the global uncertainty, i.e. including the uncertainty linked to the choice of estimation method.

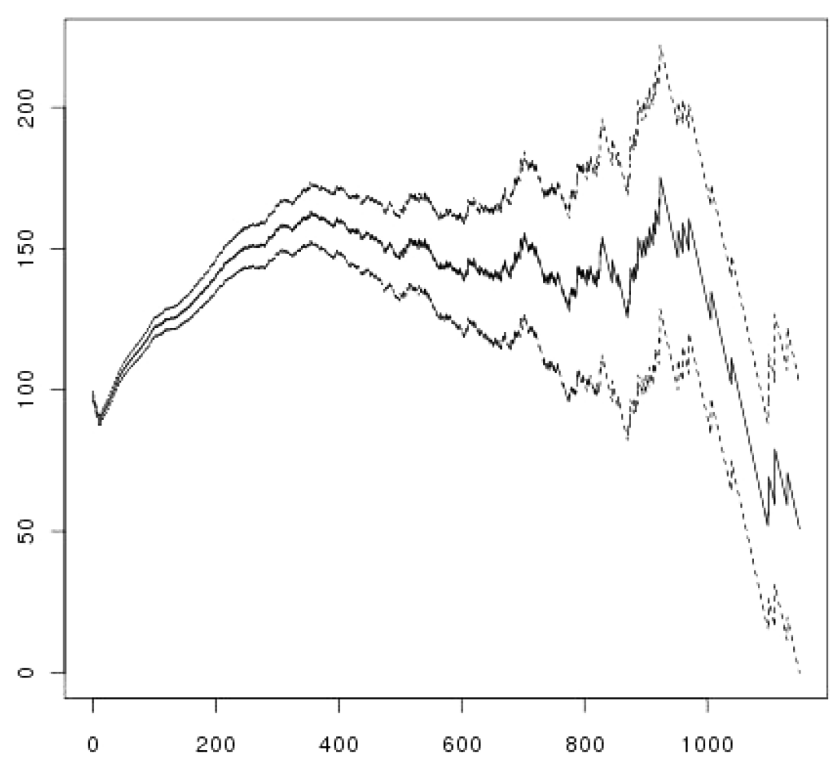

Figure 3. Mean residual life plot and associated $95 \%$ confidence interval. Horizontally: threshold, vertically: mean excess function.

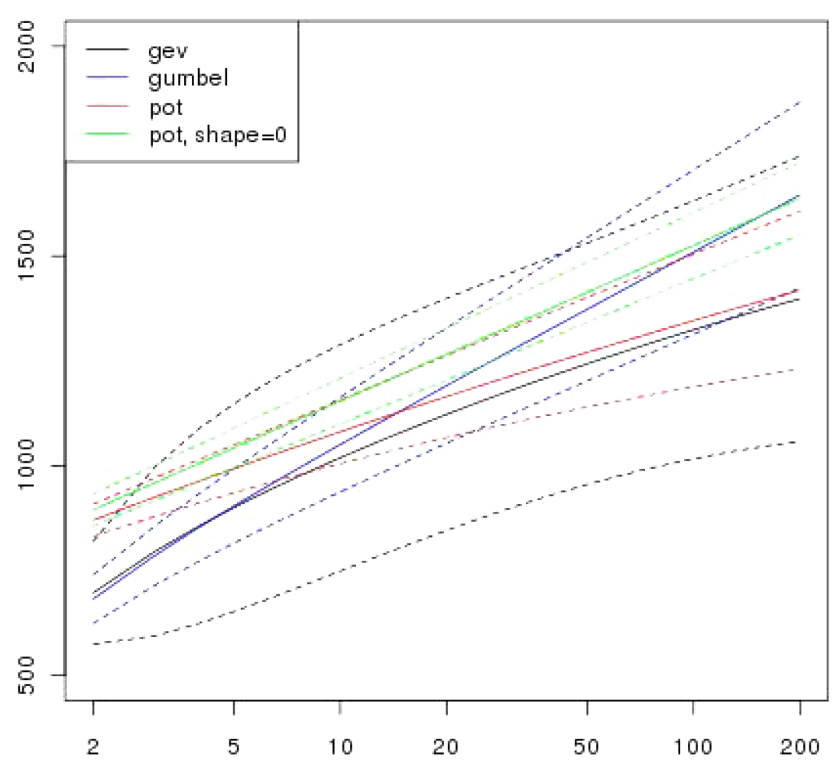

Figure 4. Overall findings with confidence intervals. Horizontal: return times. Vertical: estimated flow rate.

\section{Guiding action}

Results show that it is difficult in the considered situation to obtain accurate reliable flow rates for rare or exceptional events. We can see that flow-rate estimates with a $95 \%$ confidence interval (Figs. 4 and 5) vary between $920 \mathrm{~m}^{3} \mathrm{~s}^{-1}$ (GEV lower limit) and $1767 \mathrm{~m}^{-3} \mathrm{~s}^{-1}$ (Gumbel - upper limit).

Therefore, a risk management policy based merely on controlling the hazard is just not possible for Besançon. Risk management of rare events must be integrated in regions 


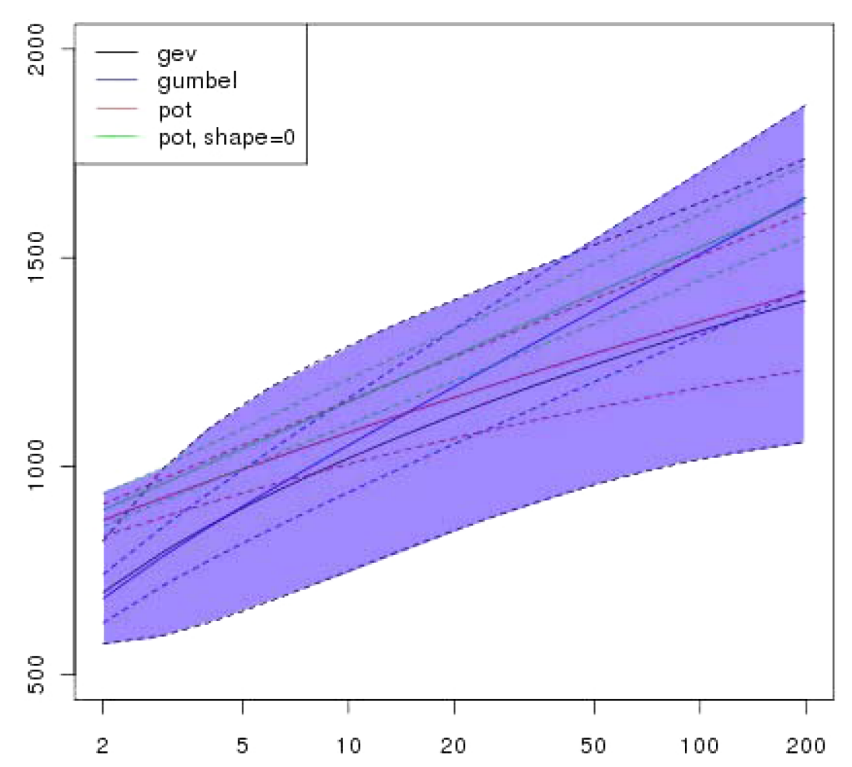

Figure 5. With $95 \%$ confidence, the hazard is located in the blue zone. Horizontal: return times. Vertical: estimated flow rate.

where work needs to be done on adapting the issues at stake and urban systems.

\subsection{Initiating strategic reflection}

Questions clearly need to be raised on the strategy for implementing resilience. This strategy can be defined as the art of directing and coordinating actions for attaining an objective. Strategic reflections cover analysis, decision-making and strategic action. Strategic reasoning seems to be the appropriate solution for implementing resilience as it enables the complex nature of urban elements and resources to be integrated into the data concerning the problem to be solved. Having or not having sufficient resources available can seriously influence the way objectives are defined. Reflections on resources also concern the virtues of what already exists and on the means of benefitting from them.

Development of an integrative approach to the strategic reflection concept is important for implementing resilience. It enables strategic reflection to be envisaged as a global training and strategy development process that is comprised of interacting stages of analysis, decision-making and action.

"If analysis can be considered to be the quintessence of reflection, we must also consider that action is a form of reflection in itself.

Taking action means adapting, modelling and transforming intellectual concepts (decisions) into results that can be materially exploited depending on the conditions encountered when they are implemented. Under these conditions, action includes reflection; it is a form of reflection" (Torset, 2005).
Strategic reflection is based on analyses; it is nourished with, and formalized by, decisions and is enriched or renewed by action. It then offers a homogeneous frame of analysis for building up a strategy, from initial strategic notions through to the results obtained by actions.

- Strategic analysis: Strategic analysis is developed by characterizing regions requirements during and after crises on the one hand, and on the basis of the regions' resources and capacities on the other.

- New knowledge on modes of resilience and its organizational tools can be obtained by analysing already encountered situations. Innovation factors for strengthening resilience are also a source of information for the analysis.

- Strategic reflection (at a tactical level) concerns decision-making and tools for decision-making (and will also concern sustainability assessments for the strategies proposed at present.

- Action (at an operational level) is materialized by experimenting and debate on the evaluation of results.

As far as strategic analysis is concerned, the resilience of urban systems passes via specific approaches centred on smaller scales. The strategic analysis should help understand the hazards for the city and also the importance of critical infrastructure in the urban operation.

\subsection{Urban component typology}

The first action concerns the material components of an urban system as they play a crucial role before, during and after the crisis. Protection objectives must also be defined depending on the role played by the different urban components during flooding. Tools and methods of analysis now enable us to improve the way we can identify and locate these urban components and their functions (Prévil et al., 2003). In the Besançon catchment, three types of urban component have been identified where efforts must be made for designing a more resilient city (Fig. 6):

- urban components of a strategic nature, such as emergency centres, the gendarmerie and the town hall whose function is to shelter the persons who will be managing emergency situations and to provide logistical and institutional support during the crisis;

- urban components of an aggravating nature such as classified installations for environmental protection, hydrocarbon storage centres, etc. Should they fail, these component elements will increase risks. It is important to know these component elements and take action beforehand to avoid the consequences of an initial disruption becoming any more serious due to a domino effect (for example, pollution resulting from non-protected stocks, industrial accidents, etc.); 
(a)

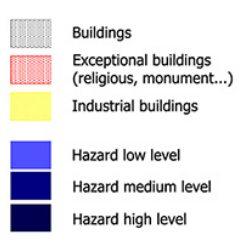

(b)

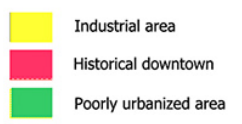

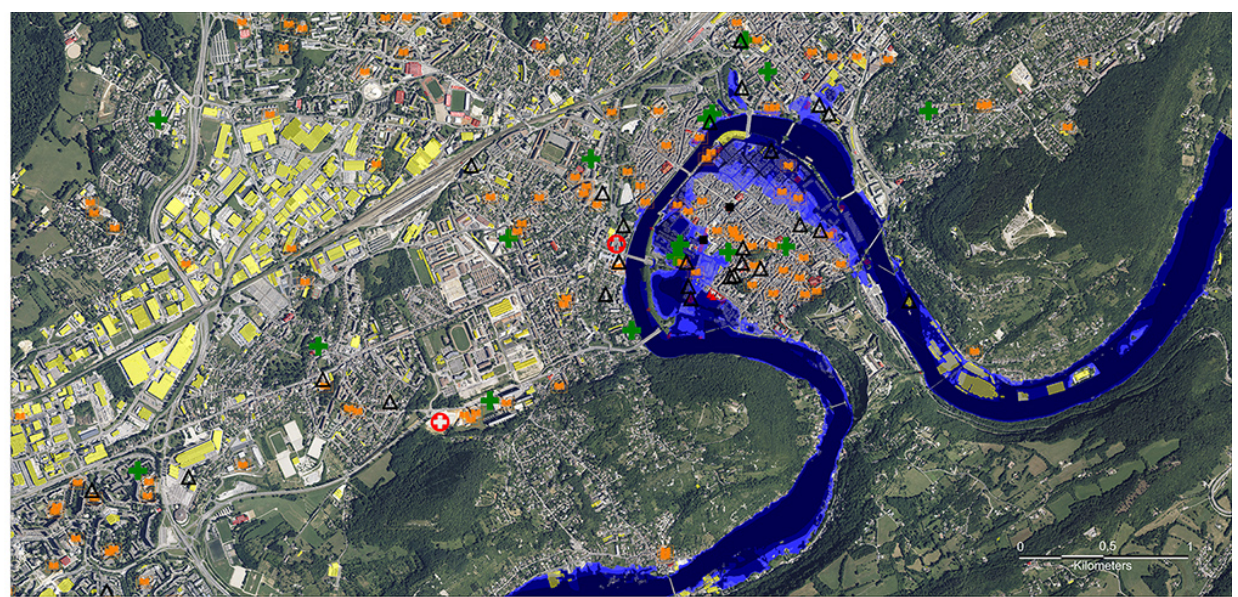

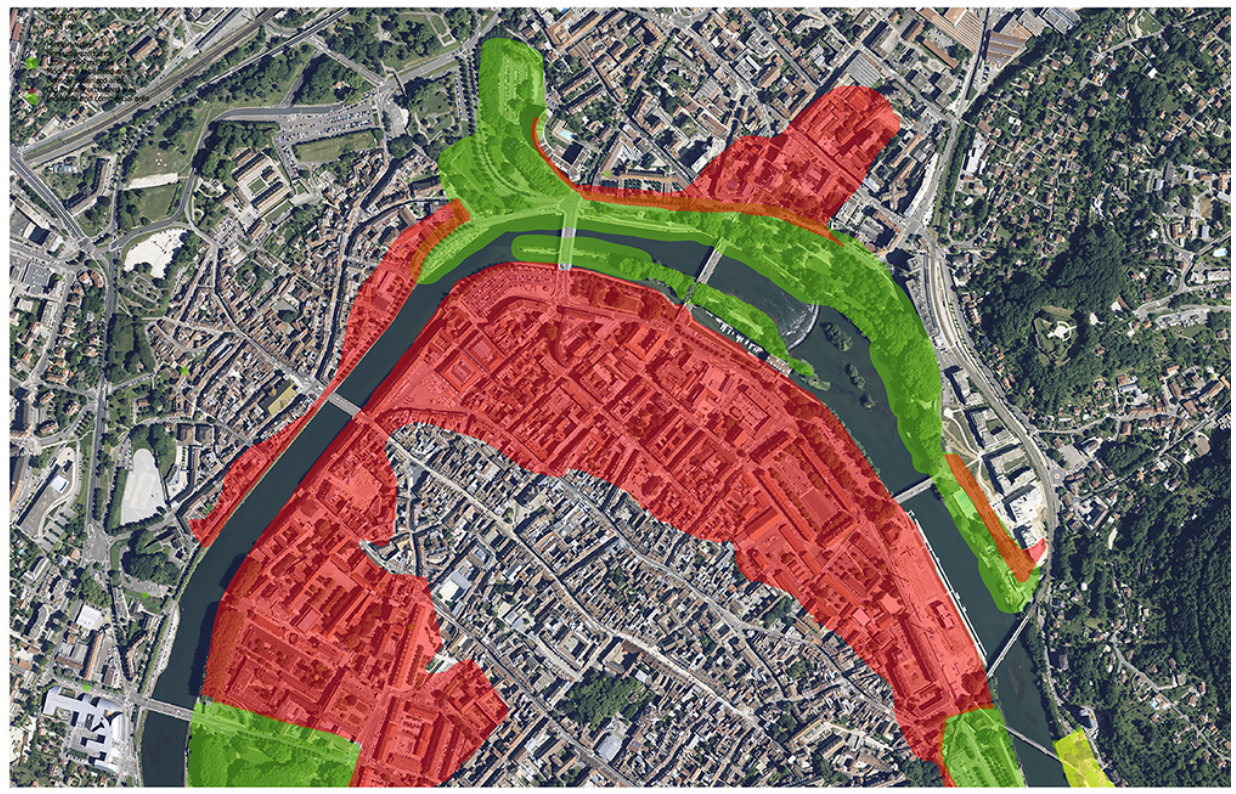

Figure 6. (a) Map of urban components; (b) city center land use in hazard area.

- urban components of a minimizing nature: for example, refuges guaranteeing better resilience. These components generally offer protection against the risks and disruptions in which they are involved, but they can also generate risks or undergo important damage which will make emergency and post-crisis management less effective.

In this way, spatialization, simulations and 3-D views can facilitate the way in which inherited or potential vulnerabilities are taken into account when defining urban projects. These tools also provide information on the flow rate at which urban components are liable to be flooded. Material measures can then make them less vulnerable.

\subsection{Approaching resilience via urban systems}

For defining resilience objectives other than those concerning components, reflections must also be made on the way cities operate. Present-day technical urban networks are highly vulnerable; they possess great potential for suffering from damage. They are also sources of vulnerability on the scale of the urban system, as the way the city operates largely depends on the fact they operate satisfactorily. Two important and interconnected notions can be highlighted by analysing the behaviour of urban technical networks:

- the critical infrastructure notion where "critical" is synonymous with "essential" or "vital". A critical infrastructure can be defined as a set of installations and 
services that are necessary for the city (ASCE, 2009) to operate: their failure is a menace for the safety, economy, life style and public health of a city, a region or even a state;

- the notion of network interdependence: most critical infrastructures interact with each other. These interactions are often complex and unrecognized, because they go beyond the limits of the system in question.

Two types of interaction can be singled out when analysing interdependent critical infrastructures:

- interactions within a single critical infrastructure (energy, sewerage or road network);

- interactions between different critical infrastructures (McNally et al., 2007), which requires a network of networks to be analysed (macro-network).

The least failure can have a knock-on effect on the whole system (Robert et al., 2009; Robert and Morabito, 2009; Serre, 2011). Therefore, analysis of interdependencies requires scales to be changed in order to analyse the component elements of a system (fine-scale) followed by the relations between different systems (a wider meta-system scale): a critical infrastructure is initially analysed as a system in itself and then, on a more widely encompassing scale, as a system of critical infrastructures (macro-network). A conceptual Spatial Decision Support System model is required for analysing the resilience of these technical systems (Balsells Mondejar et al., 2013). This model is based on three capacities (Fig. 7):

- The capacity for resisting a disruption resulting from material damage to networks following a hazard. The more a technical system is materially damaged, the more probable it will be that the system will dysfunction globally and the more difficult it will be to put it back into service. Operating reliability notions provide methods of determining damage to the system and taking account of interdependencies.

- The capacity to absorb a disruption, which depends on the alternatives that the network can offer following the failure of one or more of its component elements. For example, when a transport network is damaged, traffic will be transferred to routes that are alternatives to the initial itinerary. The more different routes there are, the less the disruption will be felt (Gleyze and Reghezza, 2007). These are alternatives that enable service continuity to be maintained and the network to operate in degraded mode. Methods resulting from the graph theory provide interesting answers.

- The capacity to recover, which is essential for a system to be resilient. For a network, recovery may simply be the time required for putting a damaged com-

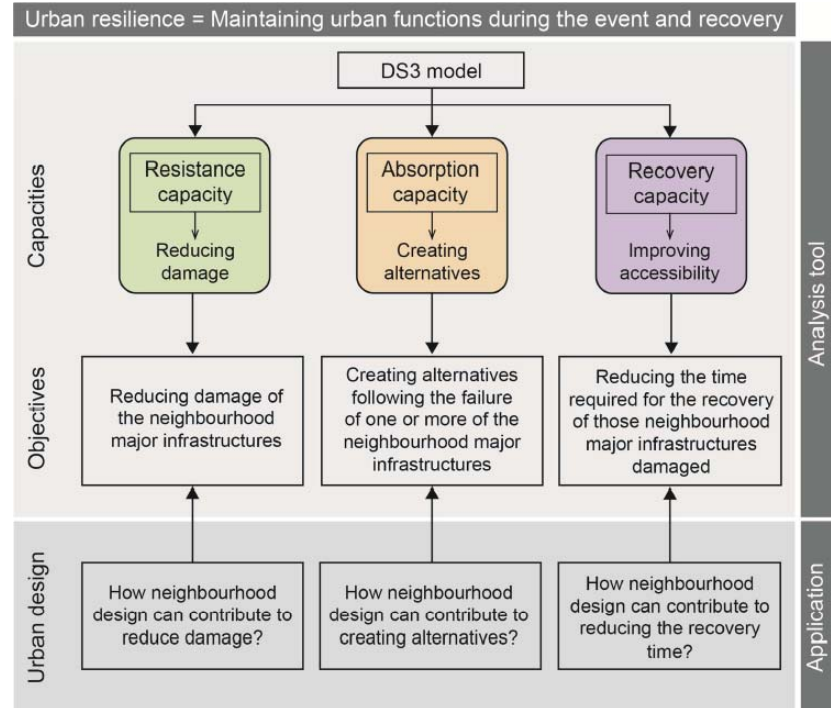

Figure 7. Application of conceptual Spatial Decision Support System model to the neighbourhood level (Balsells Mondéjar et al., 2013).

ponent back into service. In this case, purely technical aspects are conjugated with more organizational aspects. Recovery also concerns the accessibility of services needed for putting the network and any potentially damaged components back into service. The aim is to use spatial elements of analysis rather than organizational elements that require a great deal more information: recovery capacity assessments can be made with the help of geographic information sciences.

Strategic reflection could make decisions which will then be translated into action. This decision could concern a panel of return period and also estimating extreme flow rates using the extreme-value methods presented above and statistical uncertainty. This also implies setting those strategies in a long-term sustainable development context where societies will have to learn to live with natural disasters within their local area.

\subsection{Approaching by means of awareness}

Urban and industrial development in risk areas are kept under control by means of regulations. State policy is also based on prevention aspects. This principally concerns fostering a culture of risk: how can education and remembrance make local inhabitants aware of a proven risk? Responsibility for reducing flood risks involves a common culture shared between State services, the mayor and local authorities, public bodies, associations and citizens.

Work must be done in common not only for developing collective awareness of the causes, but also, and above all, for creating the collective and individual actions that need to 
be set up for protecting human life and reducing the vulnerability of services and property.

In Besançon, State services have created an online database for storing references (press articles, photographs, plans, etc) on historic floods and making them available to the public. Anyone can consult the database and even add new elements to it. An Internet site acting as a flood observatory, which contains a certain number of documents and map-based initiatives, is also available. On the scale of the Doubs River watershed, exhibitions give local inhabitants information and a booklet containing texts from 1910, as well as postcards are also available. They show how inhabitants managed to organize themselves, relying on mutual solidarity both for lighting and heating, or even for crossing waterfilled streets and transporting fresh supplies to isolated persons. The city centre was isolated and the only way of transporting people outside the loop made by the Doubs River and back inside was via the bridge-keeper's shuttle system. The extent to which day-to-day life was hindered for two days is clearly visible, as well as the time needed to return to normal. What would the effects of this flood be today, taking into account our increasing vulnerability? In 1910, it was stocks of wood that settled under the La République bridge. Today, we would most certainly find other equally troublesome products jamming the river: wrecked cars, tanks and containers, as well as all sorts of other debris.

\section{Conclusions}

An approach to uncertainty in hazard evaluation via different mathematical models for extreme values makes us aware of our knowledge status and guides our reflections as to how to implement resilience measures. When the level of uncertainty is important, which is the case for Besançon, it would appear to be an error and economically impossible to envisage resilience just by keeping the hazard under control by means of heavy structural solutions. On the contrary, using the whole region as a starting point for a vulnerability analysis enables us to recreate different geographical levers that have a decisive influence on risk situations: links between different scales, time frames, participants' roles and interests in a dynamic, non-static perspective. Therefore, carrying out an "autopsy" on resilience from a regional point of view presupposes the need to question the priorities that need to be identified in the system and which influence the way the system operates and the risks that exist. This approach should enable us to identify, characterize and classify areas where vulnerability is created and disseminated within a given territory. It is fundamental to concentrate on these areas when developing prevention policies inasmuch as they are capable of disrupting, compromising or even interrupting the operation and development of a territory.

The resilience strategy is a complement to hazard reduction and anticipation strategies. It requires risk to be actively appropriated by the persons involved, especially local populations, and for preventive actions (surveillance, alerts, etc.) to be developed alongside protection actions. Under these conditions, urban planning cannot be separated from an organizational dimension.

Acknowledgements. Edited by: T. Glade

Reviewed by: V. Becue and one anonymous referee

\section{References}

Adger, W. N., Dessai, S., Goulden, M., Hulme, M., Lorenzoni, I., Nelson, D. R., Naess, L. O., Wolf, J., and Wreford, A.: Are there social limits to adaptation to climate change?, Clim. Change, 93, 335-354, 2008.

ASCE: Guiding Principles for the Nation's Critical Infrastructure, ISBN 978-0-7844-1063-9, 42 p., 2009.

Balsells Mondéjar, M., Barroca, B., Amdal, J. R., Diab, Y., Becue, V., and Serre, D.: Analysing urban resilience through alternative stormwater management options: application of the conceptual Spatial Decision Support System model at the neighbourhood scale, Water Sci. Technol., 68, 2448-2457, 2013.

Barroca, B.: Risque et vulnérabilités territoriales - Les inondations en milieu urbain, University of Marne-la-Vallée, PhD thesis, 340p., 2006 (in French).

Barroca, B., Bernardara, P., Mouchel, J. M., and Hubert, G.: Indicators for identification of urban flooding vulnerability, Nat. Hazards Earth Syst. Sci., 6, 553-561, doi:10.5194/nhess-6-553-2006, 2006.

Bernardara, P., Schertzer, D., Sauquet, E., Tchiguirinskaia, I., and Lang, M.: Flood probability distribution tail: how heavy is it?, Stoch. Environ. Res. Risk Assess., 22, 107-122, 2008.

Birkmann J., Cardona O. D., Carreno M. L., Barbat A. H., Pelling M., Schneiderbauer S., Kienberger, S., Keiler, M., Alexander, D., Zeil, P., and Welle, T.: Framing vulnerability, risk and societal responses: the MOVE framework, Nat. Hazards, 67, 193-211, 2013.

Ceresetti, D., Ursu, E., Carreau, J., Anquetin, S., Creutin, J. D., Gardes, L., Girard, S., and Molinié, G.: Evaluation of classical spatial-analysis schemes of extreme rainfall, Nat. Hazards Earth Syst. Sci., 12, 3229-3240, doi:10.5194/nhess-12-32292012, 2012.

Coles, S.: An Introduction to Statistical Modeling of Extreme Values, Springer Series in Statistics, Springer, 2001.

EEA: Impacts of Europe's changing climate - 2011 indicator-based assessment European Environment Agency, 2011.

Gardes, L. and Girard, S.: Conditional extremes from heavy-tailed distributions: An application to the estimation of extreme rainfall return levels, Extremes, 13, 177-204, 2010.

Gaume, E., Livet M., Desbordes M., and Villeneuve, J.-P.: Hydrological analysis of the river Aude, France, flash flood on 12 and 13 November 1999, J. Hydrol., 286, 135-154, 2004.

Gleyze, J.-F. and Reghezza, M.: La vulnérabilité structurelle comme outil de compréhension des mécanismes d'endommagement, Géocarrefour, 82, 17-26, 2007 (in French). 
Klein, R. J. T., Nicholls, R. J., and Frank, T.: Resilience to natural hazards: how useful is this concept?, Environ. Hazards, 5, 35-45, 2004.

Lang, M., Perret C., Renouf E., Sauquet E., and Paquier A.: Incertitudes sur les débits de crue, Colloque SHF valeurs rares et extrêmes de précipitations et de débits pour une meilleure maîtrise des risques, Lyon, Publications SHF, 2006 (in French).

McNally, R. K., Lee, S.-W., Yavagal, S., and Xiang, W.-N.: Learning the critical infrastructure interdependencies through an ontology-based information system, Environ. Plann. B, 34, 1103-1124, 2007.

Milman, A. and Short, A.: Incorporating resilience into sustainability indicators : An example for the urban water sector, Glob. Environ. Change, 18, 758-767, (2008).

Neves, C. and Fraga Alves, M. I.: Reiss and Thomas' automatic selection of the number of extremes, Comput. Stat. Data Anal., 47, 689-704, 2004.

Payrastre, O.: Faisabilité et utilité du recueil de données historiques pour l'étude des crues extrêmes de petits cours d'eau. Etude du cas de quatre bassins versants affluents de l'Aude, Thèse de l'Ecole Nationale des Ponts et Chaussées, p. 202, 2005 (in French).

Payrastre, O., Gaume, E., and Andrieu, H.: Use of historical data to assess the occurrence of floods in small watersheds in the French Mediterranean area, Adv. Geosci., 2, 313-320, doi:10.5194/adgeo-2-313-2005, 2005.

Prévil, C., Thériault, M., and Rouffignat, J.: Analyse multicritère et SIG pour faciliter la concertation en aménagement du territoire: vers une amélioration du processus décisionnel?, Cahiers de géographie du Québec, 47, 35-61, 2003 (in French).
Robert, B. and Morabito, L.: Réduire la vulnérabilité des infrastructures essentielles, Lavoisier 2009 (in French).

Robert, B., Pinel, W., Pairet, J.-Y., Rey, B., and Coeugnard, C.: Organizational Resilience - Concepts and evaluation method, Montréal: Centre Risque \& Performance, 2009.

Romero-Lankao P. and Dodman D.: Cities in transition: transforming urban centers from hotbeds of GHG emissions and vulnerability to seedbeds of sustainability and resilience: Introduction and Editorial overview, Curr. Opin. Environ. Sustain., 3, 113120, 2011.

Romero Lankao, P. and Qin, H.: Conceptualizing urban vulnerability to global climate and environmental change, Curr. Opin. Environ. Sustain., 3, 142-149, 2011.

Serre, D.: La ville résiliente aux inondations Méthodes et outils d'évaluation, p. 173, Université Paris-Est, 2011 (in French).

Serre, D. and Barroca, B.: Preface "Natural hazard resilient cities", Nat. Hazards Earth Syst. Sci., 13, 2675-2678, 2013.

Torset, C.:La réflexion stratégique, objet et outil de recherche pour le management stratégique ?, 14. conférence internationale de management stratégique, Angers, France, juin 2005. (in French)

Zevenbergen, C., Cashman, A., Evelpidou, N., Pasche, E., Garvin, S. L., and Ashley, R.: Urban Flood Management, London, UK: Taylor and Francis Group, 2011. 